\title{
Regenerative Cell Therapy for Corneal Endothelium
}

\author{
Alena Bartakova • Noelia J. Kunzevitzky • \\ Jeffrey L. Goldberg
}

Published online: 28 June 2014

(C) Springer Science + Business Media New York 2014

\begin{abstract}
Endothelial cell dysfunction as in Fuchs dystrophy or pseudophakic bullous keratopathy and the limited regenerative capacity of human corneal endothelial cells (HCECs) drive the need for corneal transplant. In response to limited donor corneal availability, significant effort has been directed toward cell therapy as an alternative to surgery. Stimulation of endogenous progenitors or transplant of stem cell-derived HCECs or in vitro-expanded, donorderived HCECs could replace traditional surgery with regenerative therapy. Ex vivo expansion of HCECs is technically challenging, and the basis for molecular identification of functional HCECs is not established. Delivery of cells to the inner layer of the human cornea is another challenge: different techniques, from simple injection to artificial corneal scaffolds, are being investigated. Despite remaining questions, corneal endothelial cell therapies, translated to the clinic, represent the future for the treatment of corneal endotheliopathies.
\end{abstract}

Keywords Corneal endothelial dysfunction . Regenerative medicine - Cell therapy · Magnetic cell delivery $\cdot$ Human corneal endothelial cells $\cdot$ Stem cells

A. Bartakova · N. J. Kunzevitzky · J. L. Goldberg ( $\square$ ) Shiley Eye Center, University of California San Diego, 9415 Campus Point Drive \#0946, La Jolla, CA, USA e-mail: jlgoldberg@ucsd.edu

A. Bartakova

e-mail: abartakova@ucsd.edu

N. J. Kunzevitzky

Emmecell, Key Biscayne, FL 33149, USA

\section{Introduction}

The Cornea: A Clear Window into the Eye

The cornea is a $0.5 \mathrm{~mm}$ thick at the center, 1-mm-thick peripherally, transparent avascular tissue that, together with the sclera, forms the outer portion of the eye. Together with the tear film that covers its outer surface, the cornea is responsible for two-thirds of the refractive capacity of the eye. In contact with the external environment, the cornea plays an important part in protecting deeper ocular structures against injury and infection [1]. Thus, an insult to any of the components of the cornea may have an important impact on vision.

The cornea is composed of three cellular layers separated by two acellular membranes [2]. Each layer plays a specific part in facilitating optimal light transmission. The corneal epithelium represents the first defense against environmental insults, and throughout life, corneal epithelial cells are able to regenerate after injury. The intermediate stromal layer, mostly composed of extracellular matrix, nerve fibers and keratocytes, represents $90 \%$ of the total corneal thickness and confers shape and structural integrity to the cornea. The stroma is transparent, but this depends on a balance of water and electrolyte content, which are regulated by the innermost corneal endothelial cell layer.

\section{Corneal Endothelium: A Barrier to Maintain Corneal Transparency}

The corneal endothelium consists of a $4-\mu \mathrm{m}$-thick monolayer of polygonal cells (human corneal endothelial cells, HCECs), separated from the stroma by the Descemet's membrane. These highly metabolic cells form a barrier in 
part via tight junctions and demonstrate simple diffusion, facilitated diffusion and active transport mechanisms [3] that together establish a dynamic balance allowing fluid and nutrients to pass into the stroma, and drawing excess fluid and waste products out via active ATP- and bicarbonate-dependent ion pumps [4-6]. As a result, the stromal water content remains at a level that optimizes corneal transparency.

To perform this essential function, a minimal HCEC functional capacity is required, which depends on HCEC quantity (or density) and quality. On average, the human corneal endothelial layer has 3,000 cells $/ \mathrm{mm}^{2}$. This number varies throughout life, spanning from $\sim 4,000 / \mathrm{mm}^{2}$ in newborns to $\sim 2,000 / \mathrm{mm}^{2}$ in older adults, with an average decrease in central endothelial cell density of $0.5 \% / y e a r$ $[7,8,9 \cdot]$. Decline in HCEC density can be further hastened by trauma including surgery and in genetic endotheliopathies. In response to minor damage or aging, HCECs are able to stretch and migrate toward a de-cellularized area, bridging gaps in the endothelial barrier. Only a very limited number of HCECs, however, are able to proliferate in vivo. Indeed, the vast majority of HCECs are arrested in the G1 phase of the cell cycle after week 5-6 of human gestation $[10,11]$. This may be explained by a relative lack of promitogenic factors, contact inhibition and the presence of mitotic inhibitors such as TGF- $\beta_{2}$ in the aqueous humor [12-14•]. Together, these are thought to explain why trauma, disease or other injury leading to corneal endothelial damage is potentially irreversible.

\section{When Things Go Wrong: Corneal Endotheliopathies,} Current Treatments and Limitations

Corneal blindness is the fourth leading cause of blindness worldwide [15]. A subset of corneal blindness is the consequence of significant, irreversible HCEC loss. Of these, the two most common causes are trauma, most frequently related to eye surgery [16, 17], and genetic disorders such as Fuchs dystrophy [18, 19]. Fuchs dystrophy is a lateonset, slowly progressive, bilateral genetic disorder characterized by abnormal corneal endothelial cells, the presence of guttae and corneal thickening. As the pathology progresses, the guttae become confluent, the endothelium loses its barrier function and the cornea becomes edematous and opaque, leading to vision loss [20,21].

Currently, the only treatment available for HCEC insufficiency is corneal transplant, replacing either all the corneal layers (penetrating keratoplasty) or just the endothelial side of the cornea [22]. This latter option better preserves the structural integrity of the cornea. To replace the corneal endothelial layer, posterior lamellar corneal transplant is the preferred technique, with two main variants: Descemet's stripping automated endothelial keratoplasty (DSAEK) and
Descemet's membrane endothelial keratoplasty (DMEK). The surgery consists in stripping the damaged endothelial layer and Descemet's membrane and inserting the donor graft, composed of Descemet's membrane and endothelium with (DSAEK) or without (DMEK) a thin layer of adjacent stroma. Both methods preserve the patient's superficial corneal layers, thus avoiding surface irregularities and suture-related complications; however, long-term outcomes are mixed [23].

Another clinically available method for corneal replacement is the keratoprosthesis or artificial corneal transplant. This is commonly reserved for high-risk patients with multiple graft failures. Keratoprostheses suffer from multiple postoperative complications such as inflammation, corneal melt and interface problems, and glaucoma development, and imposes rigorous, life-long postoperative care [24].

All of the above-described surgical treatments are complicated and require highly trained specialists with well-developed surgical infrastructure. Despite using only donor tissue that matches very strict criteria [25], outcomes are weakened by complications including immune rejection [26, 27]. Moreover, access to treatment is limited by cost and by scarcity of donor tissue, problems that will be exacerbated by the aging of the general population and concomitant increase in patient need. These limitations of cornea transplant surgery make the investigation for new treatment methods a pressing challenge for ophthalmology research.

\section{Boosting Endogenous HCEC Proliferation and/ or Function: Topical Therapies}

One approach to treat corneal endotheliopathies is to take advantage of the remaining cells, using a topical therapy that would decrease endothelial cell loss and/or increase the ability of the remaining endothelial cells to migrate, adhere, proliferate and/or perform their "pump" functions more effectively. Such a therapy could delay need for surgery and thereby make surgical intervention a last resort treatment. Studies have reported pro-growth effects of different topically delivered growth factors on HCECs in vitro [28] and in vivo [29]. None of these approaches, however, have yet been translated to the clinic, although experience through short case series and early-phase testing is beginning to move human testing forward. For example, one of the more exciting candidates is the class of inhibitors of Rho-kinase (also called ROCK inhibitors). The proliferative potential of HCECs in vitro and in vivo was studied using the Rho-kinase inhibitor Y-27632, administered in the form of eye drops in rabbit and primate corneal injury models [30,31], and in a subsequent Phase I, 
human clinical study [32•]. Results suggested that topical ROCK inhibitor Y-27632 slowed the progression of endothelial cell degeneration and led to restoration of normal endothelial cell counts after endothelial injury in vivo. Indeed, the exact mechanism(s) by which ROCK inhibition increases HCEC proliferation is unknown. One set of data implicated activation of PI-3 kinase, with subsequent p-27 pathway downregulation [33], but these data raise concern for potentially pro-fibroblastic effects of ROCK, given that PI-3 kinase activation has been linked to endothelial-mesenchymal transition (EnMT) (discussed further below) [34]. Moreover, other data show no effect of ROCK inhibition on HCEC proliferation, both in vitro and ex vivo [35]. In humans, the response to ROCK treatment, as shown in one small patient cohort study, showed variability and of course with smaller numbers was not conclusive [32•]. Certainly long-term studies will be hotly anticipated, as there is no information yet about the safety and long-term efficacy of these topically applied molecules for corneal disease.

\section{Cell Replacement Therapies to Treat Corneal Endothelium}

In parallel, curative approaches are being developed that seek to supplement the depopulated endothelial cell layer by new, functionally competent cells. There are three potential sources of HCECs for the treatment of corneal edema: corneal endothelial progenitors, stem cell-derived CECs and allogeneic, terminally differentiated HCECs purified and expanded in vitro from a cadaveric donor cornea. Here, we will review these sources and discuss their potential use in regenerative medicine.

\section{Corneal Endothelial Progenitors and Stem Cell-Derived CECs}

Stem cell therapies have been extensively pursued for multiple organs and tissues throughout the human body, including for the corneal epithelium and the retina, however, corneal endothelial therapies based on stem cells have been, until recently, less well studied. Given the potential immune rejection problems and the tedious and uncertain process of HCEC culture (discussed below), stem cells would present a major set of potential advantages in preventing immune rejection and avoiding limitations of corneal graft tissues or corneal endothelial cell availability.

Generally speaking, stem cells are characterized by their source and their capacity for proliferation and differentiation. Embryonic stem cells (ESCs), derived from embryological tissues and broadly thought to be unlimited in their capacity for self-renewal and pluripotency, have multiple advantages and have been extensively exploited in research. However, they retain a potential risk of tumorigenicity and immune rejection. Also, the origin of embryonic stem cells derived from embryologic tissue raises ethical questions concerning their use in human therapy, and this concern has hindered their study as a potential therapeutic tool.

These latter concerns are lessened with induced pluripotent stem cells (iPSCs), which are stem cells derived directly from adult tissues and genetically reprogrammed to induce pluripotency $[36,37]$. These cells represent an unlimited supply of autologous cells, bypassing the problem of immune rejection. However, retroviral or lentiviral vectors used for iPSC engineering [38•] represent a major safety concern, with potential deleterious effects possibly leading to oncogenesis [39-43•]. Moreover, some studies have shown that iPSCs retain the epigenetic memory of their tissue of origin [44•]. This phenomenon leads to questions regarding the degree of pluripotency and raises concerns about the differentiation efficiency of such cells when used in regenerative therapies. Thus, despite the great potential that resides in the use of iPSCs in research and in clinics, many questions need to be resolved. Thus, both embryonic stem cells and iPSCs, while still a critical topic in research, are undergoing further laboratory testing to transition from bench to bedside.

Adult stem cells, also called progenitor cells, are found in small niches in different adult tissues such as the bone marrow [45], adipose tissue [46], heart [47], muscle [48], retina [49], corneal limbus [50, 51] and trabecular meshwork [52]. In contrast to ESCs or iPSCs, progenitor cells are not pluripotent but retain a high degree of plasticity, and their autologous nature renders them ideal for smallscale regenerative medicine applications [53-55]. Such applications mainly seek to replace depleted cells from a tissue using progenitor cells from the same tissue, organ or system, thus minimizing tumorigenic risks and immune reaction rejections. However, many difficulties persist, and each step of the isolation, expansion, survival and integration of the progenitor stem cells is a challenge, which may explain their limited use thus far.

In the eye, different niches of progenitor cells have been discovered and studied [51, 56॰], with a particular emphasis on retinal progenitor cells [57, 58] and corneal limbal epithelial progenitor cells, used for the regeneration of the corneal epithelium [50, 59-62]. Corneal endothelial precursor cells have, until recently, evaded study. Located in a small niche in Schwalbe's ring, the peripheral region between the cornea and the anterior portion of the trabecular meshwork, these cells have been first observed in a monkey model in the early 1980s [63]. Morphologically, these cells do not resemble trabecular meshwork or corneal endothelial cells and present stem cell morphological 
features, such as small cell size and high nucleus-to-cytoplasm ratio. Hypothesized to differentiate either into corneal endothelial cells or trabecular meshwork cells, or potentially both, these cells have received an increasing amount of attention in the past decade, bringing out the idea that the corneal endothelium does possess a limited resource of peripherally localized pluripotent cells, conferring a regenerative ability to the endothelial layer under specific circumstances $[64,65]$. This observation has been supported by other studies, suggesting that corneal endothelial cells derived from the periphery of the cornea are more numerous and demonstrate better survival than centrally located cells [66-68]. Moreover, stem cell markers such as Oct3/4, Wnt, Pax6 and Sox2, together with telomerase activity, have been detected and showed increased expression upon endothelial injury [69, 70]. Recently, several studies have, with some success, isolated and propagated animal and human endothelial progenitor cells, using a stem cell isolation sphere culture assay [71-73]. A young cell population was recently isolated using the same assay, hinting at the presence of dividing cells in the human corneal endothelium [74•]. These precursor cells have been successfully used in several animal studies to treat endothelial dysfunction, either by direct cell therapy $[72,75]$ or as part of a corneal endothelial scaffold [76].

Multilayered cell clusters have also been observed at the periphery of the cornea and are morphologically different from the surrounding HCECs [56•]. They express higher levels of stem cell markers such as Nestin and Telomerase and less of the differentiation markers ZO- 1 and $\mathrm{Na}+/ \mathrm{K}+$ ATPase by immunostaining [56 ${ }^{\circ}$. Although other studies did not observe any difference between peripheral and central HCEC proliferation rates in vitro [77], this study supported the presence of peripheral niches of stem-like cells, which could be a potential starting point for therapeutic approaches for corneal and vision restoration.

The use of progenitor cells, as a cell therapy or to coat artificial graft materials, has great potential, for example, minimizing risks of rejection if derived from each patient. However, given the very specific microenvironment these cells need to thrive and proliferate, and their very small initial numbers, in vitro expansion and in vivo human applicability remain important areas of future study. As an alternative, use of progenitor cells from extraocular origins is being explored-specifically, cells found in the bone marrow and adipose tissue. Recently, a number of groups have attempted to restore corneal transparency in animal models of corneal edema using umbilical cord blood and amniotic fluid [78, 79] and bone marrow stem cells [80], suggesting that extraocular adult stem cells could be applied to the treatment of corneal disorders. While methods to transdifferentiate stem cells into HCECs are being studied [81, 82•, 83, 84], little is known about the function and tumorigenic potential of these HCEC-like cells.

\section{Purified HCECs from Donor Corneas}

A more direct approach to overcome the shortage of donor corneas and the cumbersome transdifferentiation of other cells into HCECs is to directly inject HCECs obtained from a donor cornea into the anterior chamber. This idea requires HCECs to overcome their in vivo G1 mitotic arrest and proliferate in vitro, which has been demonstrated by a number of independent groups $[68,85]$. A number of isolation methods and culture techniques have been described $[10,86,87,88,89 \bullet]$. Briefly, these techniques rely on the isolation and digestion of the Descemet's membrane from a donor cornea, yielding clusters of HCECs that are then placed in culture. Separation of the cells from the membrane is an essential step to achieve good monolayer formation in vitro, and different ways of corneal endothelial tissue dissociation have been described, using either enzymes such as dispase, trypsin or collagenase that degrade the extracellular matrices and loosen intercellular junctions [88•, 90, 91•], or fine dissection methods combined with non-enzymatic reagents such as ethylenediamine tetraacetic acid (EDTA) to dissociate the cells [68, $92,93]$. A two-step peel-and-digest procedure developed in 2004 may be the most used approach in current practice [87]. Non-enzymatic techniques yield a reasonable number of cells per cornea with less cell damage, but are prone to contamination by stromal keratocytes. Different media, enriched in serum, antibiotics and growth factors, as well as multiple different substrates have been tested for their ability to promote the survival and expansion of HCECs [77, 87, 88•, 94-98].

Nevertheless, HCECs are difficult to culture, and although current in vitro cell expansion techniques, including ones used by our laboratory [99], yield high counts of HCECs, in culture, they can be passaged only a limited number of times before senescence or, more frequently, fibroblastic conversion known as EnMT becomes evident [85, 88•]. Morphologically, during EnMT, cells become elongated, form cytoplasmic projections and appear disorganized with variable sizes and shapes (Fig. 1), leading to the disruption of the cellular monolayer, loss of cell-cell contact inhibition, as well as changes in the extracellular matrix composition and ultimately loss of function. The molecular basis for this phenomenon is not clearly understood. A recent study using rat corneal endothelial cells implicated the involvement of the Notch pathway and successfully used the Notch inhibitor $\mathrm{N}$-[N(3,5-difluorophenacetyl)-L-alanyl]-S-phenylglycine $t$ butyl ester (DAPT) to inhibit EnMT [100]. Other molecular pathways, involving TGF- $\beta$, PI-3 kinase and fibroblast 
Fig. 1 a Cultured in vitro, HCECs maintain their characteristic cobblestone-like morphology in early passages. b With increased number of passages, HCECs lose their characteristic morphology, undergo EnMT and become fibroblastic

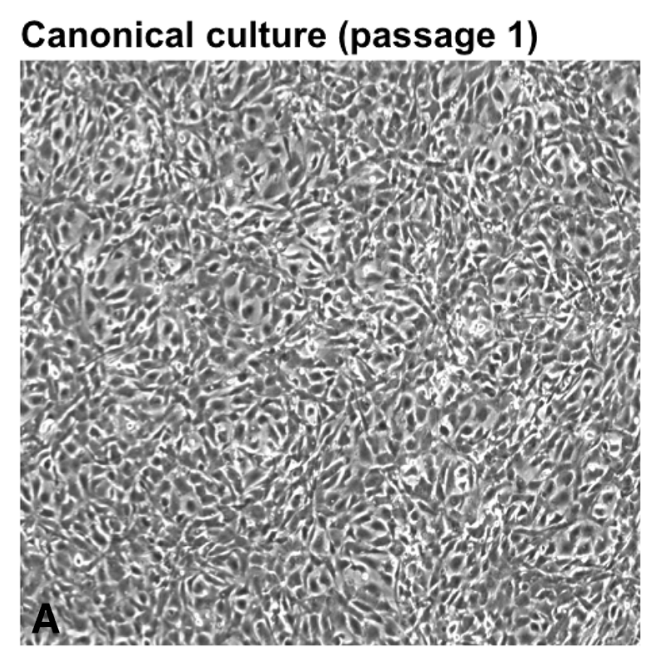

\section{Fibroblastic culture (passage 5)}

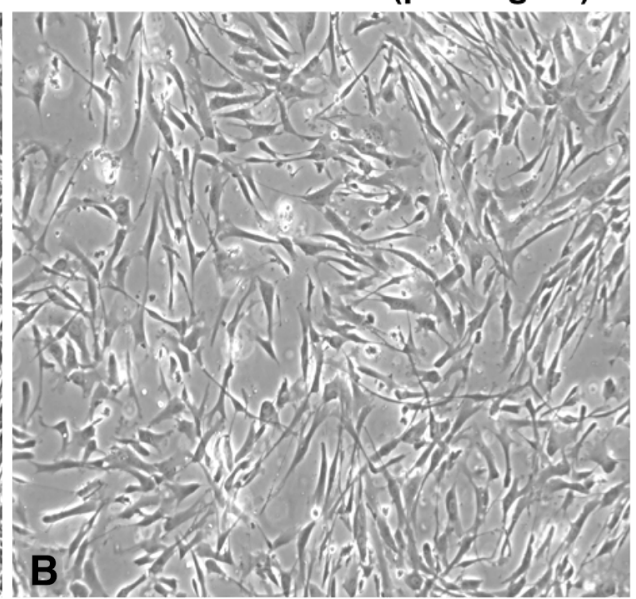

growth factor 2 (FGF2), are thought to participate in EnMT $[34,101,102 \cdot 103,104]$; the trigger that activates these pathways remains, however, a mystery, and no definitive method to prevent EnMT in HCECs currently exists. Overall, current criteria for identifying and methods for transplanting functional HCECs remain important investigative goals, and more work needs to be done in order to develop a solid basis for identifying functional cells for successful human corneal endothelial cell therapy.

Besides optimal isolation and culture techniques, optimal HCEC cultures also depend on the initial quality of the donor cornea and the donor tissue preservation. Advanced donor age results in decreased endothelial cell count and viability [87]. Other factors such as the cause of death, the general medical history and the medication taken by the donor affect initial endothelial cell density and thus impact culture success [29, 77, 87, 102•]. Recently, in a group of 64 patients, Parekh et al. demonstrated that, although not immediately affecting endothelial cell count of the donor corneas, an extended time between death and preservation of the donor tissue has a significant impact on endothelial cell survival after transplantation. Despite these restrictions, however, corneas deemed unsuitable for transplant that are redirected toward corneal endothelial cell therapy research yield perfectly adequate cultures, an encouraging observation for the potential of cell therapy, both from increasing the therapeutic benefit derived from a single cornea toward more than one recipient, and from increasing the amount of usable donor tissue.

Besides the possibility of expanding HCECs in vitro, several groups have explored the possibility of regenerating damaged corneas in vivo, showing endothelial layer repopulation after injury. These studies also explored the challenge of optimal delivery of corneal endothelial cells to the injured eye, using either in vitro engineered corneal endothelial sheets [30], or injecting cells directly to the anterior chamber [31]. Moreover, research efforts are being directed toward increasing the survival and proliferation of endothelial cells used for cell therapy: In a recent study, cultivated rabbit endothelial cells were combined with a ROCK inhibitor to treat induced corneal edema in rabbits [105]. None of these studies, however, used HCECs, and as other mammals' endothelial cells are known to have greater regenerative potential in vivo, HCEC-based studies will be required to solidify the applicability of these results.

Delivering Cells Toward the Target: Artificial Scaffolds or Direct Cell Delivery

As described above, significant effort is being directed toward the development of multilayered artificial corneal scaffolds, consisting of matrices that can be coated with HCECs, human corneal progenitor cells or differentiated non-ocular progenitor cells, and/or corneal stromal and epithelial cells. Such artificial structures would give support to the uniform growth of the seeded cells and could be used as a functional artificial graft, bypassing donor tissue limits and ensuring durable vision restoration. Numerous substrates have been used and tested in vitro and in animal models [106-114•]. In vivo use of bioengineered materials may be limited by changes in graft transparency and immune infiltration, and the grafting itself would remain a complicated surgical procedure. This approach still requires a well-developed and characterized cell culture and coating protocol and does not replace the need for endothelial cell or progenitor cell culture. Its main advantages reside in a more controlled delivery of cells to the eye.

An alternative solution is to simply inject HCECs and target their localization within the eye. Prior literature suggests that moving these cells in a magnetic field may represent an interesting approach. For example, after 
incorporating raw iron filings, rabbit corneal endothelial cells were transplanted into a rabbit model of endothelial cell dysfunction, and localized successfully to the cornea, with disappearance of edema $[115,116]$. In an ex vivo transplant model, HCECs were loaded with magnetite oxide superparamagnetic particles (SPMs) onto human corneas in the presence of an external magnetic field [117]. HCECs with SPMs migrated toward the magnet in a dosedependent manner and integrated with the recipient ex vivo corneas. Normal intraocular pressure (IOP) values suggested no adverse effects on the surrounding trabecular meshwork.

Other independent groups have demonstrated similar efficacy in cell delivery including in rabbit models in vivo $[115,116]$. Our recent data using magnetic nanoparticles in HCEC cultures compared magnetic and non-magnetic cells. Viability, identity and function of the magnetic cells did not differ from the non-magnetic controls. Moreover, the magnetic HCECs could be moved within a magnetic field (data under review). The absence of magnetic nanoparticle toxicity on HCECs in vitro matched our published data on a lack of toxicity when the nanoparticles were injected into rodent eyes in vivo [118•, 119]. By targeting injected HCECs to the endothelium with a uniform magnetic field, this cell therapy approach may decrease the potential risks of adverse effects such as trabecular meshwork clogging and increased IOP. Of course, more in vivo studies are necessary to assess such cell delivery approaches for translation to human trials.

Overall, corneal endothelial cell therapy is a technique that relies on the culture and expansion of corneal endothelial cells derived from a donor cornea, and their delivery to and integration with the recipient's damaged corneal endothelium. If successful, this elegant approach has the potential to increase access to corneal therapy by treating multiple patients with one donor cornea and to decrease the complexity of the intervention. Potential for immune rejection and cell culture challenges, specifically EnMT, remains major challenges for this approach, and more work is still needed to establish solid bases for a robust identification of functional corneal endothelial cells, to evaluate the safety and efficacy of the therapy and to perfect delivery methods.

\section{Conclusion}

Corneal endothelial dysfunction is a major cause of blindness worldwide, and surgical treatment presents challenges, including limited donor tissue and a requirement for highly specialized infrastructure. Thus, there is a significant clinical need to develop therapies that could overcome these challenges. Corneal endothelial cell therapies using HCECs derived from donor corneas present advantages of well-developed culture techniques that permit expansion of HCECs with a relatively high rate of success. Other cell sources, such as corneal progenitors or stem cell populations, may prove advantageous in generating larger cell numbers although proper differentiation needs to be assured. Finally, promotion of endogenous corneal endothelial regeneration by pharmaceutical therapies on one hand, or the optimization of cell delivery by engineering scaffolds or artificial grafts on the other, may yet contribute critical steps toward this dynamic evolution of novel corneal therapies.

Disclosure Jeffrey L. Goldberg and UCSD Shiley Eye Center have received research grants from the National Eye Institute and Research to Prevent Blindness, Inc. Noelia J. Kunzevitzky and Jeffrey L. Goldberg are inventors on pending patent applications assigned to Emmecell.

Human and Animal Rights and Informed Consent This article does not contain any studies with human or animal subjects performed by any of the authors.

\section{References}

Papers of particular interest, published recently, have been highlighted as:

- Of importance

1. Vaughan and Asbury's general ophthalmology, Chap. 1. Anatomy and Embryology of the Eye, 18th ed. 2013.

2. Mescher AL. Junqueira's basic histology: text and atlas, Chap. 23. In: The eye and ear: special sense organs, 13th ed. 2013.

3. Foets BJ, van den Oord JJ, Volpes R, Missotten L. In situ immunohistochemical analysis of cell adhesion molecules on human corneal endothelial cells. Br J Ophthalmol. 1992;76: 205-9.

4. Maurice DM. The location of the fluid pump in the cornea. J Physiol (Lond). 1972;221:43-54.

5. Bourne WM. Clinical estimation of corneal endothelial pump function. Trans Am Ophthalmol Soc. 1998;96:229-39 discussion 239-242.

6. Srinivas SP. Cell signaling in regulation of the barrier integrity of the corneal endothelium. Exp Eye Res. 2012;95:8-15. doi:10. 1016/j.exer.2011.09.009.

7. Murphy C, Alvarado J, Juster R, Maglio M. Prenatal and postnatal cellularity of the human corneal endothelium. A quantitative histologic study. Invest Ophthalmol Vis Sci. 1984;25:312-22.

8. Bourne WM, Nelson LR, Hodge DO. Central corneal endothelial cell changes over a ten-year period. Invest Ophthalmol Vis Sci. 1997;38:779-82.

9. - Gipson IK. Age-related changes and diseases of the ocular surface and cornea. Invest Ophthalmol Vis Sci. 2013;54: ORSF48-53. doi:10.1167/iovs.13-12840. Short review summarizing age-related changes of the eye surface.

10. Joyce NC, Meklir B, Joyce SJ, Zieske JD. Cell cycle protein expression and proliferative status in human corneal cells. Invest Ophthalmol Vis Sci. 1996;37:645-55. 
11. Joyce NC, Navon SE, Roy S, Zieske JD. Expression of cell cycle-associated proteins in human and rabbit corneal endothelium in situ. Invest Ophthalmol Vis Sci. 1996;37:1566-75.

12. Joyce NC, Harris DL, Mello DM. Mechanisms of mitotic inhibition in corneal endothelium: contact inhibition and TGF-beta2. Invest Ophthalmol Vis Sci. 2002;43:2152-9.

13. Lu J, Lu Z, Reinach P, Zhang J, Dai W, et al. TGF- $\beta 2$ inhibits AKT activation and FGF-2-induced corneal endothelial cell proliferation. Exp Cell Res. 2006;312:3631-40. doi:10.1016/j. yexcr.2006.08.004.

14. - Joyce NC. Proliferative capacity of corneal endothelial cells. Exp Eye Res. 2012;95:16-23. doi:10.1016/j.exer.2011.08.014. This very comprehensive review describes the multiple factors that influence the proliferative capacity of human corneal endothelial cells, as well as potential impact on novel treatment therapies.

15. Stevens GA, White RA, Flaxman SR, Price H, Jonas JB, et al. Global prevalence of vision impairment and blindness: magnitude and temporal trends, 1990-2010. Ophthalmology. 2013;120:2377-84. doi:10.1016/j.ophtha.2013.05.025.

16. Scott R. The injured eye. Philos Trans R Soc B. 2010;366: 251-60. doi:10.1016/S0161-6420(00)00024-5.

17. Garcia-Pous M, Udaondo P, Garcia-Delpech S, Salom D, DíazLlopis M. Acute endothelial failure after cosmetic iris implants (NewIris ${ }^{\circledR}$ ). Clin Ophthalmol. 2011;5:721-3. doi:10.2147/ OPTH.S18569.

18. Schmedt T, Silva MM, Ziaei A, Jurkunas U. Molecular bases of corneal endothelial dystrophies. Exp Eye Res. 2012;95:24-34. doi:10.1016/j.exer.2011.08.002.

19. Vincent AL. Corneal dystrophies and genetics in the International Committee for Classification of Corneal Dystrophies era: a review. Clin Exp Ophthalmol. 2013;42:4-12. doi:10.1111/ceo. 12149.

20. McLaren JW, Bachman LA, Kane KM, Patel SV. Objective assessment of the corneal endothelium in Fuchs' endothelial dystrophy. Invest Ophthalmol Vis Sci. 2014;55:1184-90. doi:10. 1167/iovs.13-13041.

21. Farjo AA, Brumm MV, Soog HK. Yanoff: ophthalmology, 4th ed. In: Part 4-Cornea and ocular surface diseases. 2013.

22. Price MO, Price FW Jr. Endothelial keratoplasty—a review. Clin Exp Ophthalmol. 2010;38:128-40. doi:10.1111/j.14429071.2010.02213.x.

23. Borderie VM, Boëlle PY, Touzeau O, Allouch C, Boutboul S, et al. Predicted long-term outcome of corneal transplantation. Ophthalmology. 2009;116:2354-60. doi:10.1016/j.ophtha.2009. 05.009.

24. Alqudah AA, Terry MA, Straiko MD, Greiner MA, DavisBoozer D. Immediate endothelial cell loss after penetrating keratoplasty. Cornea. 2013;32:1587-90. doi:10.1097/ICO. 0b013e3182a73822.

25. EBAA (2011) Eye Bank Association of America Medical Standards. Eye Bank Association of America; p. 1-46.

26. Wu EI, Ritterband DC, Yu G, Shields RA, Seedor JA. Graft rejection. Am J Ophthalmol. 2012;153(949-957):e1. doi:10. 1016/j.ajo.2011.10.004.

27. Anshu A, Price MO, Price FW. Risk of corneal transplant rejection significantly reduced with Descemet's membrane endothelial keratoplasty. Ophthalmology. 2012;119:536-40. doi:10.1016/j.ophtha.2011.09.019.

28. Hoppenreijs VP, Pels E, Vrensen GF, Treffers WF. Corneal endothelium and growth factors. Surv Ophthalmol. 1996;41: 155-64.

29. Nakano Y, Oyamada M, Dai P, Nakagami T, Kinoshita S, et al. Connexin 43 knockdown accelerates wound healing but inhibits mesenchymal transition after corneal endothelial injury in vivo.
Invest Ophthalmol Vis Sci. 2008;49:93-104. doi:10.1167/iovs. 07-0255.

30. Koizumi N, Sakamoto Y, Okumura N, Tsuchiya H, Torii R, et al. Cultivated corneal endothelial transplantation in a primate: possible future clinical application in corneal endothelial regenerative medicine. Cornea. 2008;27(Suppl 1):S48-55. doi:10.1097/ICO.0b013e31817f2298.

31. Koizumi N, Sakamoto Y, Okumura N, Okahara N, Tsuchiya H, et al. Cultivated corneal endothelial cell sheet transplantation in a primate model. Invest Ophthalmol Vis Sci. 2007;48:4519-26. doi:10.1167/iovs.07-0567.

32. - Okumura N, Koizumi N, Kay EP, Ueno M, Sakamoto Y, et al. The ROCK inhibitor eye drop accelerates corneal endothelium wound healing. Invest Ophthalmol Vis Sci. 2013;54:2493-502. doi:10.1167/iovs.12-11320. This article reports a positive effect of the ROCK inhibitor eye drops on corneal endothelial wound healing in a primate animal model.

33. Numata R, Okumura N, Kay EP, Nakahara M, Nakano S, et al. Rho-kinase inhibitor enhances corneal endothelial cell proliferation via p27 degradation. ARVO 2013 Annual Meeting: 1690-D0325. 2013.

34. Lee HT. FGF-2 induced by interleukin-1 through the action of phosphatidylinositol 3-kinase mediates endothelial mesenchymal transformation in corneal endothelial cells. J Biol Chem. 2004;279:32325-32. doi:10.1074/jbc.M405208200.

35. Pipparelli A, Arsenijevic Y, Thuret G, Gain P, Nicolas M, et al. ROCK inhibitor enhances adhesion and wound healing of human corneal endothelial cells. PLoS One. 2013;8:e62095. doi:10.1371/journal.pone.0062095.t002.

36. Takahashi K, Yamanaka S. Induction of pluripotent stem cells from mouse embryonic and adult fibroblast cultures by defined factors. Cell. 2006;126:663-76. doi:10.1016/j.cell.2006.07.024.

37. Zhu S, Rezvani M, Harbell J, Mattis AN, Wolfe AR, et al. Mouse liver repopulation with hepatocytes generated from human fibroblasts. Nature. 2014;508:93-7. doi:10.1038/ nature 13020.

38. • Okita K, Hong H, Takahashi K, Yamanaka S. Generation of mouse-induced pluripotent stem cells with plasmid vectors. Nat Protoc. 2010;5:418-28. doi:10.1038/nprot.2009.231. This article describes a method for reprogramming mouse embryonic fibroblasts into iPS cells by plasmid vector transfection, avoiding the use of viruses to generate pluripotent stem cells.

39. Stadtfeld M, Nagaya M, Utikal J, Weir G, Hochedlinger K. Induced pluripotent stem cells generated without viral integration. Sci Transl Med. 2008;322:943-5. doi:10.1126/science. 1161408.

40. Zhou H, Wu S, Joo JY, Zhu S, Han DW, et al. Generation of induced pluripotent stem cells using recombinant proteins. Stem Cell. 2009;4:381-4. doi:10.1016/j.stem.2009.04.005.

41. Lin T, Ambasudhan R, Yuan X, Li W, Hilcove S, et al. A chemical platform for improved induction of human iPSCs. Nat Methods. 2009;6:805-8. doi:10.1038/nmeth.1393.

42. Miura K, Okada Y, Aoi T, Okada A, Takahashi K, et al. Variation in the safety of induced pluripotent stem cell lines. Nat Biotechnol. 2009;27:743-5. doi:10.1038/nbt.1554.

43. - Abad M, Mosteiro L, Pantoja C, Cañamero M, Rayon T, et al. Reprogramming in vivo produces teratomas and iPS cells with totipotency features. Nature. 2013;502:340-5. doi:10.1038/ nature12586. This article points out the dangers related to the use of iPS cells as a therapeutic tool in vivo.

44. $•$ Kim K, Doi A, Wen B, Ng K, Zhao R, et al. Epigenetic memory in induced pluripotent stem cells. Nature. 2010;467:285-90. doi:10.1038/nature09342. This article underlines the presence of epigenetic memory in iPS cells, pointing out the limits of cell reprogramming. 
45. Ding L, Morrison SJ. Haematopoietic stem cells and early lymphoid progenitors occupy distinct bone marrow niches. Nature. 2013;495:231-5. doi:10.1038/nature11885.

46. Sivan U, Jayakumar K, Krishnan LK. Matrix-directed differentiation of human adipose-derived mesenchymal stem cells to dermal-like fibroblasts that produce extracellular matrix. J Tissue Eng Regen Med. 2014. doi:10.1002/term.1865.

47. Beltrami AP, Barlucchi L, Torella D, Baker M, Limana F, et al. Adult cardiac stem cells are multipotent and support myocardial regeneration. Cell. 2003;114:763-76.

48. Rocheteau P, Gayraud-Morel B, Siegl-Cachedenier I, Blasco MA, Tajbakhsh S. A subpopulation of adult skeletal muscle stem cells retains all template DNA strands after cell division. Cell. 2012;148:112-25. doi:10.1016/j.cell.2011.11.049.

49. Tropepe V. Retinal stem cells in the adult mammalian eye. Sci Transl Med. 2000;287:2032-6. doi:10.1126/science.287.5460. 2032.

50. Rama P, Matuska S, Paganoni G, Spinelli A, De Luca M, et al. Limbal stem-cell therapy and long-term corneal regeneration. N Engl J Med. 2010;363:147-55. doi:10.1056/NEJMoa09 05955 .

51. Pellegrini G, Golisano O, Paterna P, Lambiase A, Bonini S, et al. Location and clonal analysis of stem cells and their differentiated progeny in the human ocular surface. J Cell Biol. 1999;145:769-82.

52. Tay CY, Sathiyanathan P, Chu SWL, Stanton LW, Wong TT. Identification and characterization of mesenchymal stem cells derived from the trabecular meshwork of the human eye. Stem Cells Dev. 2012;21:1381-90. doi:10.1089/scd.2011.0655.

53. Pak J. Autologous adipose tissue-derived stem cells induce persistent bone-like tissue in osteonecrotic femoral heads. Pain Physician. 2012;15:75-85.

54. Kang K-S, Kim SW, Oh YH, Yu JW, Kim K-Y, et al. A 37-yearold spinal cord-injured female patient, transplanted of multipotent stem cells from human UC blood, with improved sensory perception and mobility, both functionally and morphologically: a case study. Cytotherapy. 2005;7:368-73. doi:10.1080/1465324 0500238160 .

55. Orlic D, Kajstura J, Chimenti S, Jakoniuk I, Anderson SM, et al. Bone marrow cells regenerate infarcted myocardium. Nature. 2001;410:701-5. doi:10.1038/35070587.

56. - He Z, Campolmi N, Gain P, Ha Thi BM, Dumollard J-M, et al. Revisited microanatomy of the corneal endothelial periphery: new evidence for continuous centripetal migration of endothelial cells in humans. Stem Cells. 2012;30:2523-34. doi:10.1002/ stem.1212. This article identifies a novel anatomic organization of human corneal endothelial cells at the periphery of the cornea, suggesting the presence of specific niches of endothelial cells. Throughout life, these cells undergo a slow migration towards the center of the cornea.

57. MacLaren RE, Pearson RA, MacNeil A, Douglas RH, Salt TE, et al. Retinal repair by transplantation of photoreceptor precursors. Nature. 2006;444:203-7. doi:10.1038/nature05161.

58. Limb GA, Daniels JT. Ocular regeneration by stem cells: present status and future prospects. Br Med Bull. 2008;85: 47-61. doi:10.1093/bmb/ldn008.

59. Schermer A, Galvin S, Sun TT. Differentiation-related expression of a major $64 \mathrm{~K}$ corneal keratin in vivo and in culture suggests limbal location of corneal epithelial stem cells. J Cell Biol. 1986;103:49-62.

60. Cotsarelis G, Cheng SZ, Dong G, Sun TT, Lavker RM. Existence of slow-cycling limbal epithelial basal cells that can be preferentially stimulated to proliferate: implications on epithelial stem cells. Cell. 1989;57:201-9.

61. Pellegrini G, Traverso CE, Franzi AT, Zingirian M, Cancedda $\mathrm{R}$, et al. Long-term restoration of damaged corneal surfaces with autologous cultivated corneal epithelium. Lancet. 1997;349: 990-3. doi:10.1016/S0140-6736(96)11188-0.

62. Li GG, Zhu YT, Xie HT, Chen SY, Tseng SCG. Mesenchymal Stem Cells Derived from Human Limbal Niche Cells. Invest Ophthalmol Vis Sci. 2012;53:5686-97. doi:10.1167/iovs.1210300.

63. Raviola G. Schwalbe line's cells: a new cell type in the trabecular meshwork of Macaca mulatta. Invest Ophthalmol Vis Sci. 1982;22:45-56.

64. Schimmelpfennig BH. Direct and indirect determination of nonuniform cell density distribution in human corneal endothelium. Invest Ophthalmol Vis Sci. 1984;25:223-9.

65. Amann J, Holley GP, Lee S-B, Edelhauser HF. Increased endothelial cell density in the paracentral and peripheral regions of the human cornea. Am J Ophthalmol. 2003;135:584-90. doi:10.1016/S0002-9394(02)02237-7.

66. Van Horn DL, Hyndiuk RA. Endothelial wound repair in primate cornea. Exp Eye Res. 1975;21:113-24.

67. Van Horn DL, Sendele DD, Seideman S, Buco PJ. Regenerative capacity of the corneal endothelium in rabbit and cat. Invest Ophthalmol Vis Sci. 1977;16:597-613.

68. Mimura T, Joyce NC. Replication competence and senescence in central and peripheral human corneal endothelium. Invest Ophthalmol Vis Sci. 2006;47:1387-96. doi:10.1167/iovs.051199.

69. Whikehart DR, Parikh CH, Vaughn AV, Mishler K, Edelhauser HF. Evidence suggesting the existence of stem cells for the human corneal endothelium. Mol Vis. 2005;11:816-24.

70. McGowan SL, Edelhauser HF, Pfister RR, Whikehart DR. Stem cell markers in the human posterior limbus and corneal endothelium of unwounded and wounded corneas. Mol Vis. 2007;13:1984-2000.

71. Yokoo S. Human corneal endothelial cell precursors isolated by sphere-forming assay. Invest Ophthalmol Vis Sci. 2005;46:1626-31. doi:10.1167/iovs.04-1263.

72. Mimura T. Comparison of rabbit corneal endothelial cell precursors in the central and peripheral cornea. Invest Ophthalmol Vis Sci. 2005;46:3645-8. doi:10.1167/iovs.05-0630.

73. Amano S, Yamagami S, Mimura T, Uchida S, Yokoo S. Corneal stromal and endothelial cell precursors. Cornea. 2006;25:S73-7. doi:10.1097/01.ico.0000247218.10672.7e.

74. - Mimura T, Yamagami S, Yokoo S, Usui T, Amano S. Selective isolation of young cells from human corneal endothelium by the sphere-forming assay. Tissue Eng Part C Methods. 2010;16:803-12. doi:10.1089/ten.TEC.2009.0608. This study describes a method of in vitro isolating young from older corneal endothelial cells using a sphere-forming assay.

75. Mimura T, Yokoo S, Araie M, Amano S, Yamagami S. Treatment of rabbit bullous keratopathy with precursors derived from cultured human corneal endothelium. Invest Ophthalmol Vis Sci. 2005;46:3637-44. doi:10.1167/iovs.05-0462.

76. Yamagami S, Mimura T, Yokoo S, Takato T, Amano S. Isolation of human corneal endothelial cell precursors and construction of cell sheets by precursors. Cornea. 2006;25:S90-2. doi:10.1097/01.ico.0000247221.95424.d7.

77. Konomi K. Comparison of the proliferative capacity of human corneal endothelial cells from the central and peripheral areas. Invest Ophthalmol Vis Sci. 2005;46:4086-91. doi:10.1167/iovs. 05-0245.

78. Liu H, Zhang J, Liu C-Y, Wang I-J, Sieber M, et al. Cell therapy of congenital corneal diseases with umbilical mesenchymal stem cells: lumican null mice. PLoS ONE. 2010;5:e10707. doi:10. 1371/journal.pone.0010707.g009.

79. Sha X, Liu Z, Song L, Wang Z, Liang X. Human amniotic epithelial cell niche enhances the functional properties of human corneal endothelial cells via inhibiting P53-survivin-mitochondria 
axis. Exp Eye Res. 2013;116:36-46. doi:10.1016/j.exer.2013.08. 008.

80. Gu S, Xing C, Han J, Tso MOM, Hong J. Differentiation of rabbit bone marrow mesenchymal stem cells into corneal epithelial cells in vivo and ex vivo. Mol Vis. 2009;15:99-107.

81. Shao C, Fu Y, Lu W, Fan X. Bone marrow-derived endothelial progenitor cells: a promising therapeutic alternative for corneal endothelial dysfunction. Cells Tissues Organs. 2011;193: 253-63. doi:10.1159/000319797.

82. - Joyce NC, Harris DL, Markov V, Zhang Z, Saitta B. Potential of human umbilical cord blood mesenchymal stem cells to heal damaged corneal endothelium. Mol Vis. 2012;18:547-64. This article demonstrates that umbilical cord blood mesenchymal stem cells are able to migrate towards regions of injured corneal endothelium, and can differentiate towards human corneal endothelium-like cells, which makes them a potential tool for human corneal endothelial cell therapy.

83. Patent WO2013/086236A2; 2013.

84. Valdez JE, Zavala J, Trevino V, Martinez E. Over-representation preliminary analysis between expressed genes in corneal endothelium and mesenchymal stem cells. ARVO 2012 Annual Meeting Abstracts: 6008/D829. 2012.

85. Joyce NC, Zhu CC. Human corneal endothelial cell proliferation: potential for use in regenerative medicine. Cornea. 2004;23:S8-19.

86. Baum JL, Niedra R, Davis C, Yue BY. Mass culture of human corneal endothelial cells. Arch Ophthalmol. 1979;97:1136-40.

87. Zhu C, Joyce NC. Proliferative response of corneal endothelial cells from young and older donors. Invest Ophthalmol Vis Sci. 2004;45:1743-51. doi:10.1167/iovs.03.

88. • Peh GSL, Toh K-P, Wu F-Y, Tan DT, Mehta JS. Cultivation of human corneal endothelial cells isolated from paired donor corneas. PLoS One. 2011;6:e28310. doi:10.1371/journal.pone. 0028310.t004. This article describes a two media culture technique to optimize the in vitro propagation of human corneal endothelial cells.

89. - Peh GS, Toh K-P, Ang H-P, Seah X-Y, George BL, et al. Optimization of successful endothelial cell culture. BMC Res Notes. 2013;6:176. doi:10.1186/1756-0500-6-176. This article proposes an optimal seeding density of not less than 10000 cells per $\mathrm{cm}^{2}$ for the successful culture and in vitro propagation of human corneal endothelial cells.

90. Engelmann K, Böhnke M, Friedl P. Isolation and long-term cultivation of human corneal endothelial cells. Invest Ophthalmol Vis Sci. 1988;29:1656-62.

91. • Peh GSL, Beuerman RW, Colman A, Tan DT, Mehta JS. Human corneal endothelial cell expansion for corneal endothelium transplantation: an overview. Transplantation. 2011;91:811-9. doi:10.1097/TP.0b013e3182111f01. A detailed review of current and past culture methods for in vitro propagation of human corneal endothelial cells.

92. Senoo T, Obara Y, Joyce NC. EDTA: a promoter of proliferation in human corneal endothelium. Invest Ophthalmol Vis Sci. 2000;41:2930-5.

93. Li W, Sabater AL, Chen YT, Hayashida Y, Chen SY, et al. A novel method of isolation, preservation, and expansion of human corneal endothelial cells. Invest Ophthalmol Vis Sci. 2007;48:614-20. doi:10.1167/iovs.06-1126.

94. Fabricant RN, Alpar AJ, Centifanto YM, Kaufman HE. Epidermal growth factor receptors on corneal endothelium. Arch Ophthalmol. 1981;99:305-8.

95. Patel SP, Bourne WM. Corneal endothelial cell proliferation: a function of cell density. Invest Ophthalmol Vis Sci. 2009;50:2742-6. doi:10.1167/iovs.08-3002.

96. de Lau W, Barker N, Low TY, Koo B-K, Li VSW, et al. Lgr5 homologues associate with Wnt receptors and mediate
R-spondin signalling. Nature. 2011;476:293-7. doi:10.1038/ nature 10337.

97. Cui Y-B, Wu J. Research progress on the negative factors of corneal endothelial cells proliferation. Int $\mathrm{J}$ Ophthalmol. 2012;5:614-9. doi:10.3980/j.issn.2222-3959.2012.05.14.

98. Nakahara M, Okumura N, Kay EP, Hagiya M, Imagawa K, et al. Corneal endothelial expansion promoted by human bone marrow mesenchymal stem cell-derived conditioned medium. PLoS One. 2013;8:e69009. doi:10.1371/journal.pone.0069009.t001.

99. Alvarez-Delfin K, Kunzevitzky NJ, Weisman AD, Merkhofer RM, Goldberg JL. A cell therapy approach to address corneal endothelial dysfunction. ARVO 2013 Annual Meeting Abstracts: 1648-D0283. 2013.

100. Li C, Dong F, Jia Y, Du H, Dong N, et al. Notch signal regulates corneal endothelial-to-mesenchymal transition. Am J Pathol. 2013;183:786-95. doi:10.1016/j.ajpath.2013.05.025.

101. Aomatsu K, Arao T, Sugioka K, Matsumoto K, Tamura D, et al. TGF- $\beta$ induces sustained upregulation of SNAI1 and SNAI2 through Smad and non-Smad pathways in a human corneal epithelial cell line. Invest Ophthalmol Vis Sci. 2011;52:2437-43. doi:10.1167/iovs.10-5635.

102. - Lee JG, Ko MK, Kay EP. Endothelial mesenchymal transformation mediated by IL-1 $\beta$ FGF-2 in corneal endothelial cells. Exp Eye Res. 2012;95:35-9. doi:10.1016/j.exer.2011.08.003. This review describes the molecular mechanisms of FGF-2 mediated EnMT in corneal endothelial cells.

103. Lee JG, Kay EP. FGF-2-mediated signal transduction during endothelial mesenchymal transformation in corneal endothelial cells. Exp Eye Res. 2006;83:1309-16. doi:10.1016/j.exer.2006. 04.007.

104. Lee JG, Kay EP. NF-B is the transcription factor for FGF-2 that causes endothelial mesenchymal transformation in cornea. Invest Ophthalmol Vis Sci. 2012;53:1530-8. doi:10.1167/iovs. 11-9102.

105. Koizumi N, Okumura N, Kinoshita S. Development of new therapeutic modalities for corneal endothelial disease focused on the proliferation of corneal endothelial cells using animal models. Exp Eye Res. 2012;95:60-7. doi:10.1016/j.exer.2011. 10.014.

106. Blake DA, Yu H, Young DL, Caldwell DR. Matrix stimulates the proliferation of human corneal endothelial cells in culture. Invest Ophthalmol Vis Sci. 1997;38:1119-29.

107. Griffith M. Functional human corneal equivalents constructed from cell lines. Science. 1999;286:2169-72. doi:10.1126/ science.286.5447.2169.

108. Chen KH, Azar D, Joyce NC. Transplantation of adult human corneal endothelium ex vivo: a morphologic study. Cornea. 2001;20:731-7.

109. Takezawa T, Ozaki K, Nitani A, Takabayashi C, Shimo-Oka T. Collagen vitrigel: a novel scaffold that can facilitate a threedimensional culture for reconstructing organoids. Cell Transplant. 2004;13:463-73.

110. Fagerholm P, Lagali NS, Merrett K, Jackson WB, Munger R, et al. A biosynthetic alternative to human donor tissue for inducing corneal regeneration: 24-month follow-up of a phase 1 clinical study. Sci Transl Med. 2010;2:46ra61. doi:10.1126/ scitranslmed.3001022.

111. Karamichos D, Funderburgh ML, Hutcheon AEK, Zieske JD, $\mathrm{Du} \mathrm{Y}$, et al. A role for topographic cues in the organization of collagenous matrix by corneal fibroblasts and stem cells. PLoS One. 2014;9:e86260. doi:10.1371/journal.pone.0086260. s001.

112. Karamichos D, Hutcheon AEK, Zieske JD. Transforming growth factor- $\beta 3$ regulates assembly of a non-fibrotic matrix in a 3D corneal model. J Tissue Eng Regen Med. 2011;5:e228-38. doi:10.1002/term.429. 
113. Mimura T, Yamagami S, Amano S. Corneal endothelial regeneration and tissue engineering. Prog Retin Eye Res. 2013;35:1-17. doi:10.1016/j.preteyeres.2013.01.003.

114. - Wu J, Du Y, Mann MM, Yang E, Funderburgh JL, et al. Bioengineering organized, multilamellar human corneal stromal tissue by growth factor supplementation on highly aligned synthetic substrates. Tissue Eng Part A. 2013;19:2063-75. doi:10.1089/ten.tea.2012.0545. This article describes a bioengineering approach that combines substrate cues with growth factor components, with the aim to develop a well-organized construct for corneal repair and regeneration.

115. Mimura T, Yamagami S, Usui T, Ishii Y, Ono K, et al. Longterm outcome of iron-endocytosing cultured corneal endothelial cell transplantation with magnetic attraction. Exp Eye Res. 2005;80:149-57. doi:10.1016/j.exer.2004.08.021.

116. Mimura T, Shimomura N, Usui T, Noda Y, Kaji Y, et al. Magnetic attraction of iron-endocytosed corneal endothelial cells to Descemet's membrane. Exp Eye Res. 2003;76:745-51. doi:10.1016/S0014-4835(03)00057-5.

117. Patel SV, Bachman LA, Hann CR, Bahler CK, Fautsch MP. Human corneal endothelial cell transplantation in a human ex vivo model. Invest Ophthalmol Vis Sci. 2009;50:2123-31. doi:10.1167/iovs.08-2653.

118. • Raju HB, Hu Y, Vedula A, Dubovy SR, Goldberg JL. Evaluation of magnetic micro- and nanoparticle toxicity to ocular tissues. PLoS One. 2011;6:e17452. doi:10.1371/journal.pone. 0017452.t002. This article demonstrates the safety of magnetic nanoparticles when used on anterior and posterior eye structures.

119. Raju HB, Hu Y, Padgett KR, Rodriguez JE, Goldberg JL. Investigation of nanoparticles using magnetic resonance imaging after intravitreal injection. Clin Exp Ophthalmol. 2011;40:100-7. doi:10.1111/j.1442-9071.2011.02651.x. 